\title{
THE IMPACT OF THE THICKNESS OF THE PERMEABLEFABRIC ON THE PARALLEL PLATE CHANNEL STREAM OF CASSON LIQUID WHEN THE DIVIDERS ARE PROVIDED WITH NON-ERODIBLE PERMEABLE LINING
}

\author{
P. JYOTHI ${ }^{1}$, L.KAVITHA ${ }^{2}$, M. ESWARA RAO ${ }^{3}$ \&D. EBENEZER ${ }^{4}$ \\ $I^{*}$ Dept. of Mathematics, Sri Venkateswara University, Tirupati, Andhra Pradesh, India \\ ${ }^{2}$ Dept. of Mathematics, School of Applied Sciences, REVA University, Bengaluru, Karnataka, India \\ ${ }^{3,4}$ Dept. of Mathematics, Saveetha Institute of Medical and Technical Sciences, Chennai, Tamil Nadu, India
}

\begin{abstract}
In this examination the impact of the thickness of the permeable fabric on the parallel plate channel stream of Casson liquid when the dividers are given with non-erodible permeable lining is considered. The governing partial momentum equation is changed to ordinary differential equation by utilizing non-dimensional amounts and fathomed it analytically. The impacts of governing parameters on the liquid speed are appeared in graphically. We examined the stream within the free stream region and permeable stream regions by utilizing Darcy law and Casson model respectively.

KEYWORDS:Casson parameter; permeable lining; parallel plate channel
\end{abstract}

Received: Jun 08, 2020; Accepted: Jun 28, 2020; Published: Aug 21, 2020; Paper Id.: IJMPERDJUN2020855

\section{INTRODUCTION}

In later a long time significant intrigued has been manifested within the study of stream past permeable media since of its application in industrial, bio-physical and hydrological issues. Within the think about of stream past a permeable fabric it is standard to utilize the no-slip boundary condition at the permeable surface where the impact of porosity is taken care of by the continuity of the typical component of velocity. Beavers and Joseph [1] examined for the primary time, this class of streams past actually porous bed with slip at the nominal surface. Krishna Murthy et al. [2-7] created thermophoresis and brownian motion impacts on three dimensional MHD slip stream of a Cassonnanofluid over an exponentially stretching sheet. MHD boundary layers slip Casson liquid stream over a dissipated extended cylinder. Slip impacts on MHD three dimensional stream of Casson liquid over an exponentially extending surface. MHD three dimensional stream of Casson liquid over an unsteady exponentially extending sheet with slip conditions. Hydromagnetic stream of Casson liquid through a vertical deformable permeable stratum with viscous dissipation and chemical reaction and impacts of heat and mass exchange stream of a Jeffrey liquid through a vertical deformable permeable stratum. Sreenadhet al. [8] explored MHD Couette stream of a Jeffrey liquid over a deformable porous layer. Impact of heat exchange on free surface stream of a Jeffrey liquid over a deformable permeable bed was examined by Eswara Rao et al. [9]. Krishna Murthy [10] displayed MHD Couette stream of Jeffrey liquid in a permeable channel with heat source and chemical reaction.

The display consider bargains with the impact of the thickness of the permeable fabric on the parallel plate channel stream of Casson liquid when the dividers are given with non-erodible permeable lining is examined. 
We examined the stream in the free stream region and permeable stream regions by utilizing Darcy law and Casson model respectively. The governing velocity equation is fathomed by closed form solution.

\section{MATHEMATICAL MODEL OF THE PROBLEM}

Consider, the consistent stream of a Casson liquid through a channel formed a channel by two inflexible impermeable parallel plates at $y=0$ and $y=h$ is spoken in Figure 1. The lower divider is secured with a homogeneous and isotropic porous fabric of thickness $h^{\prime}(\neq 0)$. Hence partitioning the stream region into two zones, Zone 1 speaks the region of the free stream between the upper impermeable divider and the nominal surface $y=h^{\prime}$ and Zone 2 indicating the region of stream through the permeable fabric.

gh the permeable fabric.

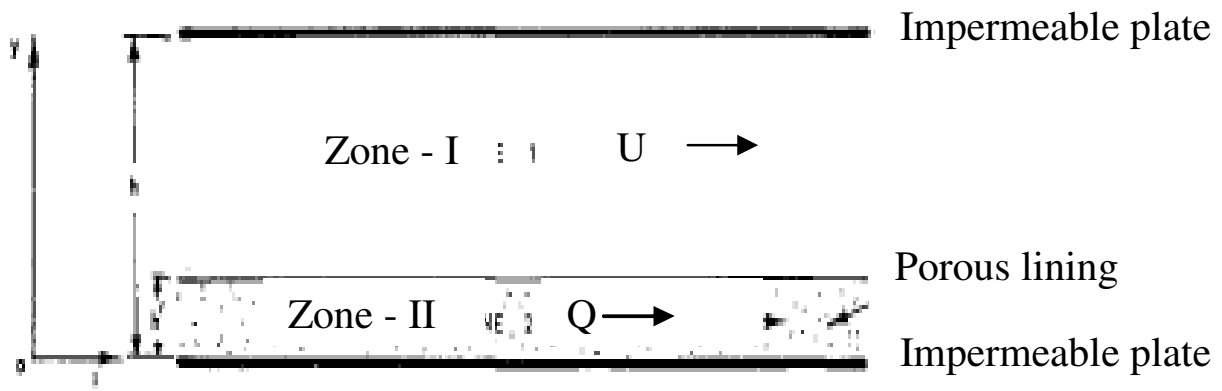

Figure 1: Physical Geometry of the Problem

The stream which is caused by a uniform pressure gradient within the longitudinal direction in both the zones is assumed to be completely created and the liquid properties are all assumed to be steady. At the point of the stream in Zone I is governed by the Navier-Stokes equation is

$$
\mu\left(1+\frac{1}{\beta}\right) \frac{\partial^{2} u}{\partial y^{2}}=\frac{\partial p}{\partial x}
$$

and that in Zone II by the Darcy law

$$
\mu\left(1+\frac{1}{\beta}\right) Q=-K \frac{\partial p}{\partial x}
$$

The limit conditions are as follows:

$$
\left.\begin{array}{l}
\begin{array}{l}
u=0 \text { at } y=h \\
\frac{\partial u}{\partial y}=\frac{\alpha}{\sqrt{K}}\left(u_{B}-Q\right) a t y=h^{\prime}
\end{array}
\end{array}\right\}
$$

The non-dimensional quantities are as follows: 


$$
v=\frac{u}{\bar{u}}, \eta=\frac{y}{h}, \xi=\frac{x}{h}, \pi=\frac{p}{\frac{1}{2} \rho \bar{u}^{2}}, R=\frac{\rho \bar{u} h}{\mu}, P=-\frac{R}{2} \frac{\partial \pi}{\partial \xi}, \sigma=\frac{h}{\sqrt{K}}, Q^{\prime}=\frac{Q}{\bar{u}}, \varepsilon=\frac{h^{\prime}}{h}
$$

Where $u$ is the velocity, $\beta$ is the Casson parameter, $p$ is the pressure, $\mu$ is the dynamic viscosity, $Q$ is the Darcy velocity, $K$ is the absolute permeability of the material, $u_{B}$ is the slip velocity at the nominal surface, $\alpha$ is the slip parameter, $h$ is the height of the channel and $h^{\prime}$ is the thickness of the porous lining, $\rho$ is the fluid density, $R$ is the Reynolds number, $\bar{u}$ is the average velocity in the channel, $\mathcal{E}$ is the thickness of the porous channel.

From equations (1) - (4) we get the following equations are

$$
\begin{aligned}
& \frac{d^{2} v}{d \eta^{2}}=-\frac{P}{\left(1+\frac{1}{\beta}\right)} \\
& Q^{\prime}=\frac{P}{\sigma^{2}\left(1+\frac{1}{\beta}\right)}
\end{aligned}
$$

The following non dimensional limit conditions are

$$
\left.\begin{array}{l}
v=0 \text { at } \eta=1 \\
\frac{d v}{d \eta}=\alpha \sigma\left(v_{B}-Q^{\prime}\right) a t \eta=\varepsilon
\end{array}\right\}
$$

Where $v_{B}$ is the slip velocity

\section{Solution of the problem}

In this paper we solved the governing equation with the closed form solution. The solution of (5) satisfying (7) is

$$
v(\eta)=(1-\eta)\left[\frac{P(1+\eta)}{2\left(1+\frac{1}{\beta}\right)}-\frac{P \varepsilon}{\left(1+\frac{1}{\beta}\right)}-\alpha \sigma v_{B}+\frac{\alpha P}{\sigma\left(1+\frac{1}{\beta}\right)}\right]
$$

Where $v_{\mathbf{B}}=\frac{P(1-\varepsilon)[\sigma(1-\varepsilon)+2 \alpha]}{2 \sigma\left(1+\frac{1}{\beta}\right)[\sigma \alpha(1-\varepsilon)+1]}, 0<\varepsilon<1$

We are interest to find the quantitative effect of slip on the flow, we calculate the

non-dimensional mass flow rate

$$
M=M_{1}+M_{2}
$$


Where $M_{1}=\int_{\varepsilon}^{1} v d \eta=\frac{P}{12} \frac{(1-\varepsilon)^{3}}{\left(1+\frac{1}{\beta}\right)}\left[\frac{4+\alpha \sigma(1-\varepsilon)-6 \alpha^{2}}{1+\alpha \sigma(1-\varepsilon)}\right]+\frac{\alpha P}{2 \sigma} \frac{(1-\varepsilon)^{3}}{\left(1+\frac{1}{\beta}\right)}=\frac{P}{12} A+\frac{P}{2} B$

and

$$
M_{2}=Q^{\prime} \varepsilon=\frac{P \varepsilon}{\sigma^{2}\left(1+\frac{1}{\beta}\right)}
$$

In order to bring out the effect of porous lining in the channel we compare $M$ with the mass flow rate $M^{*}$ in the channel in the absence of lining where

$$
M^{*}=\int_{0}^{1} v d \eta=\frac{P}{3\left(1+\frac{1}{\beta}\right)}
$$

Then the ration of the mass flow rate with and without porous lining is given by

$$
\frac{M}{M^{*}}=\frac{A}{4}+\frac{3 B}{2}+\frac{3 \varepsilon}{\sigma^{2}}
$$

\section{Results and Discussion}

In this paper we look at the affect of the thickness of the permeable fabric on the parallel plate channel stream of Casson liquid when the dividers are given with non-erodible permeable lining is considered. We examined the stream within the free stream region and permeable stream regions by utilizing Darcy law and Casson model respectively. The governing equation is solved with closed form solution. The impacts of governing parameters on the liquid speed from equation (8) are shown with the assistance of graphs for the stream in a channel with one side permeable lining.

The impact of thickness of permeable layer $\mathcal{E}$ on the liquid speed $v(\eta)$ is appeared in Figure 2. We taken note that the speed diminishes for higher values of thickness of permeable layer. The impacts of slip parameter $\alpha$ and the permeability parameter $\sigma$ on the liquid speed $v(\eta)$ are shown in Figures 3and 4. We watched that the liquid speed rot with expanding slip parameter and permeability parameter. The affect of pressure gradient $P$ on the liquid speed $v(\eta)$ is delineating in Figure 5. We have seen that the liquid speed upgrades for higher values of pressure gradient. From figure 6 speak to the impact of Casson parameter $\beta$ on the liquid speed $v(\eta)$.We uncover that the liquid speed diminishes with expanding Casson parameter. This causes yield stress. The ratio of mass stream rate $M / M^{*}$ covering one side permeable lining smothers for higher values of the porousness parameter $\sigma$. Advance for higher values of slip parameter $\alpha$ rots the ratio of mass stream rate is spoken in Figures 7 and 8.

\section{CONCLUSIONS}

In this paper the affect of the thickness of the permeable fabric on the parallel plate channel stream of Casson liquid when the dividers are furnished with non-erodible permeable lining is contemplated. We investigated the stream within the 
free stream region and permeable stream areas by utilizing Darcy law and Casson liquid model respectively. The governing equation is clarified with closed form solution. The targets of the current paper are as per the following:

- The liquid speed decreaseswith the affect of thickness of permeable layer,slip parameter and permeability parameter.

- The liquid speed upgrades with an impact of pressure gradient and Casson liquid parameter.

- The ratio of mass stream rate $M / M^{*}$ covering one side permeable lining smothers for higher estimations of the permeability parameter $\sigma$. Further for higher estimations of slip parameter $\alpha$ rots.

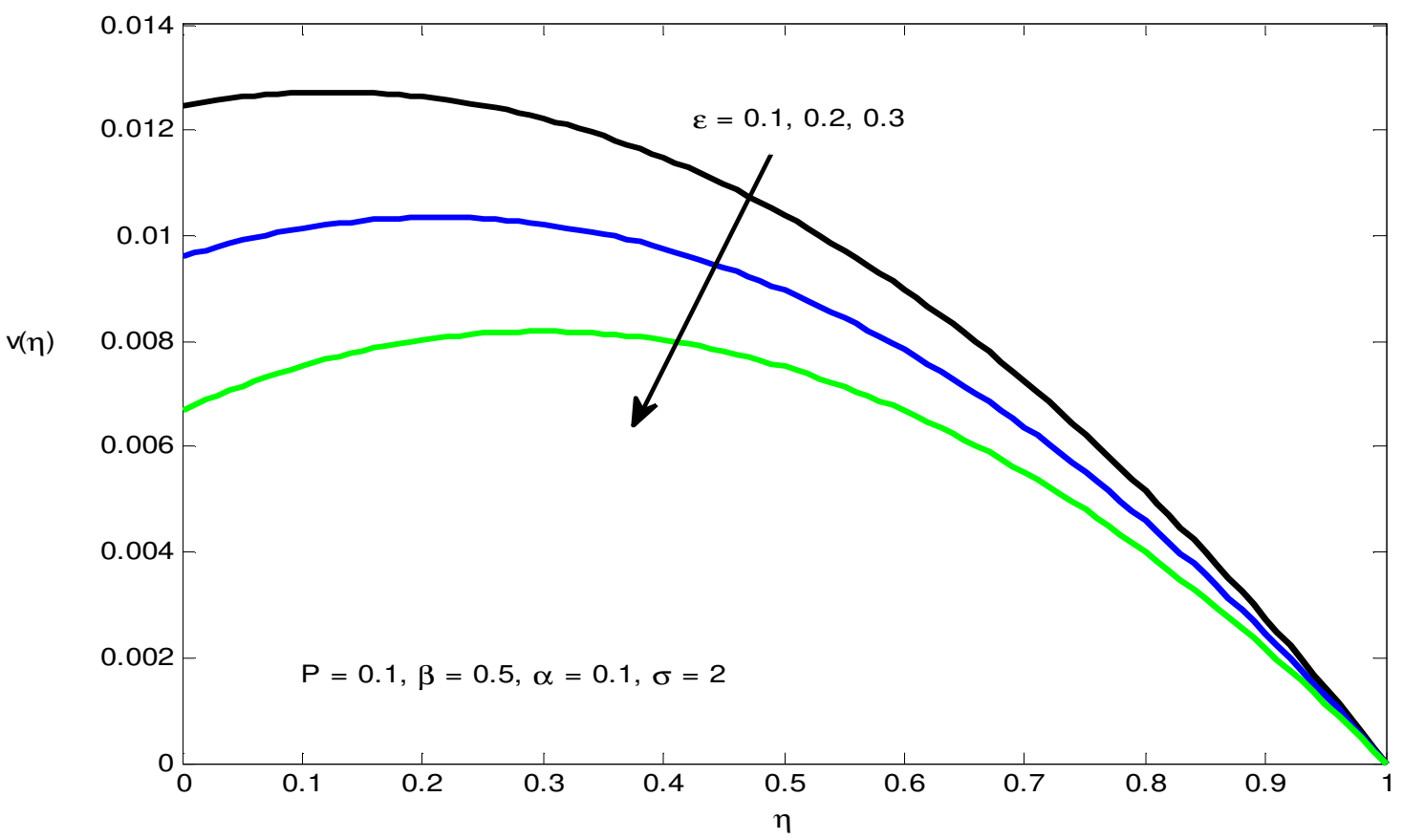

Figure 2:The Impact of $\mathcal{E}$ on the Fluid Velocity $v(\eta)$ 


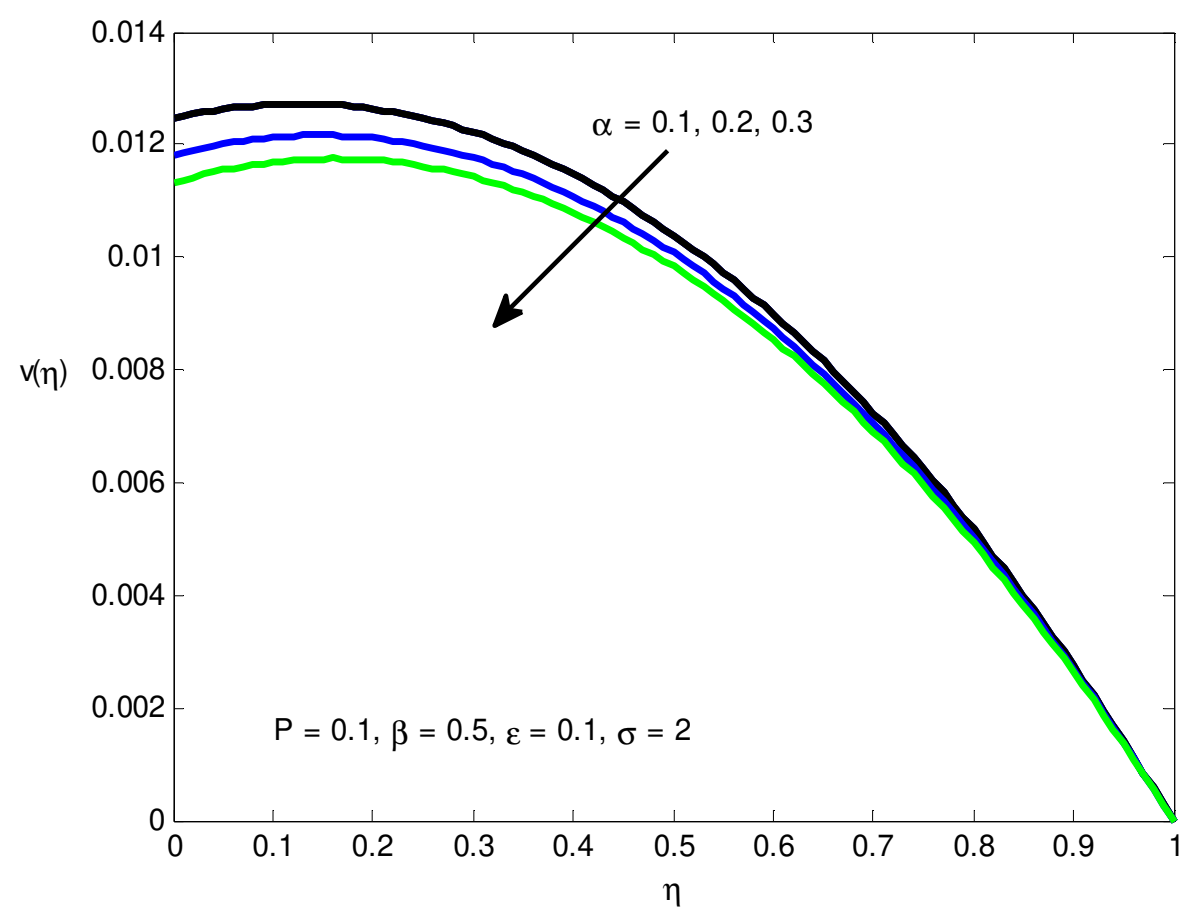

Figure 3:The Impact of $\alpha$ on the Fluid Velocity $v(\eta)$

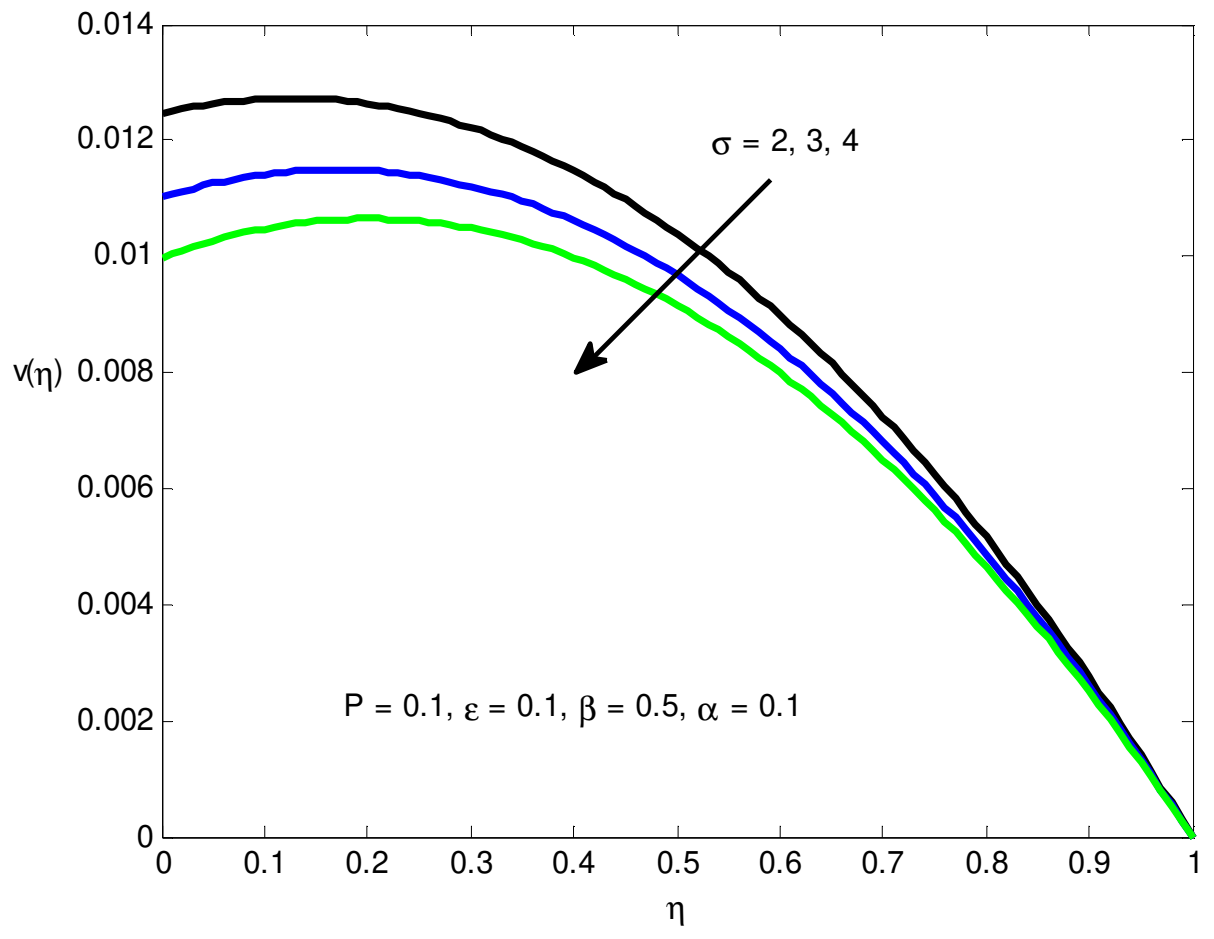

Figure 4:The Impact of $\sigma$ on the Fluid Velocity $v(\eta)$ 


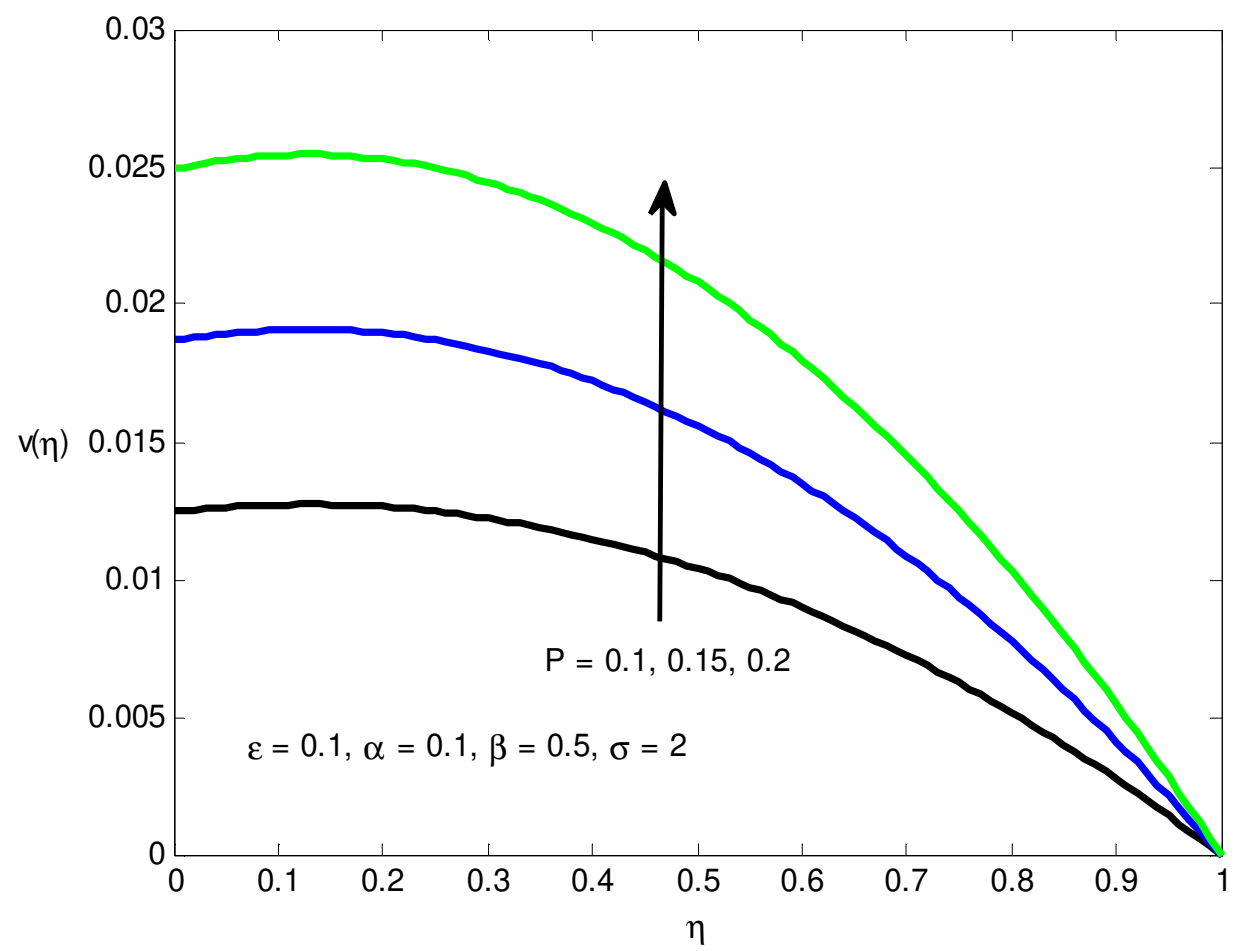

Figure 5.The impact of $P$ on the fluid velocity $v(\eta)$

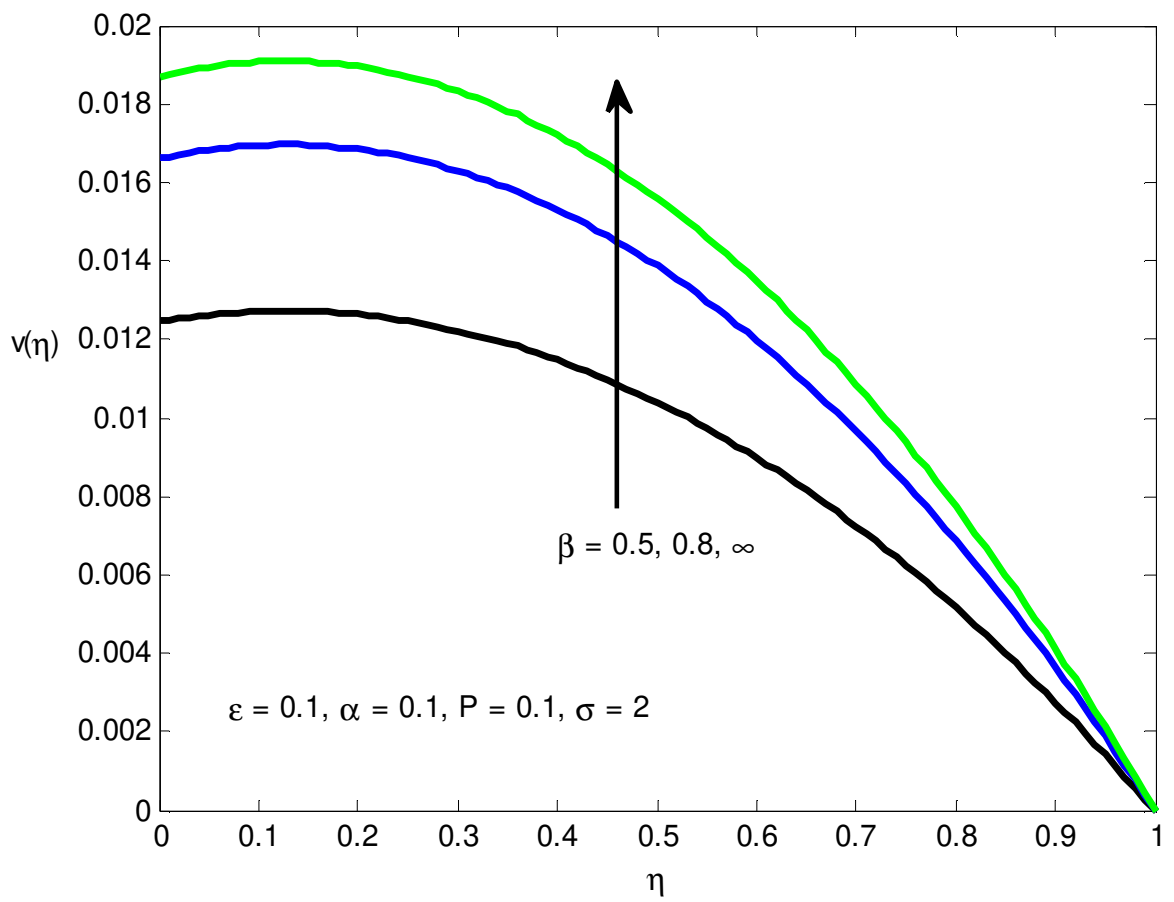

Figure 6: The Impact of $\beta$ on the Fluid Velocity $v(\eta)$ 


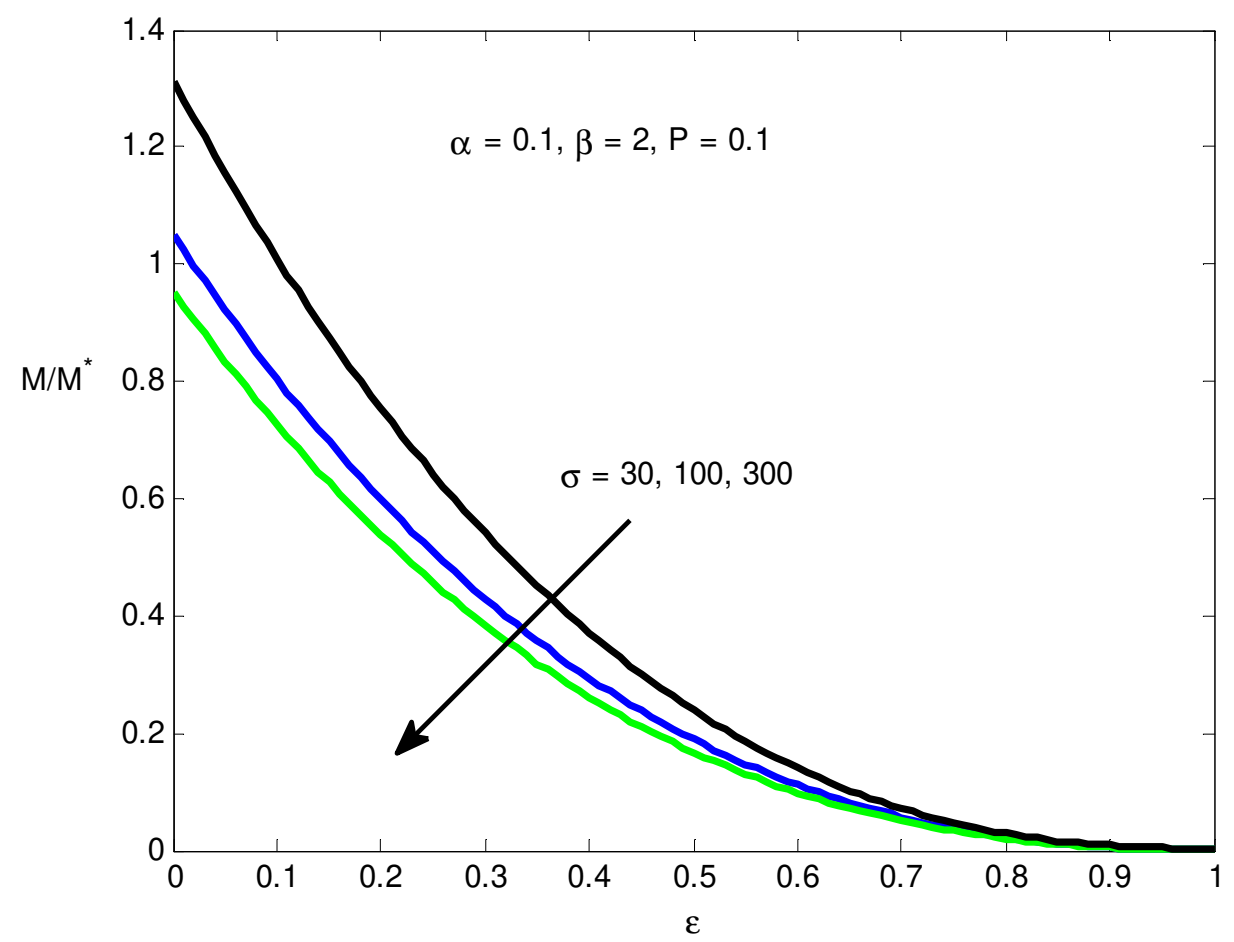

Figure 7: The Impact of $\sigma$ on the Mass Flow Rate $M / M^{*}$ for $\alpha=0.1$

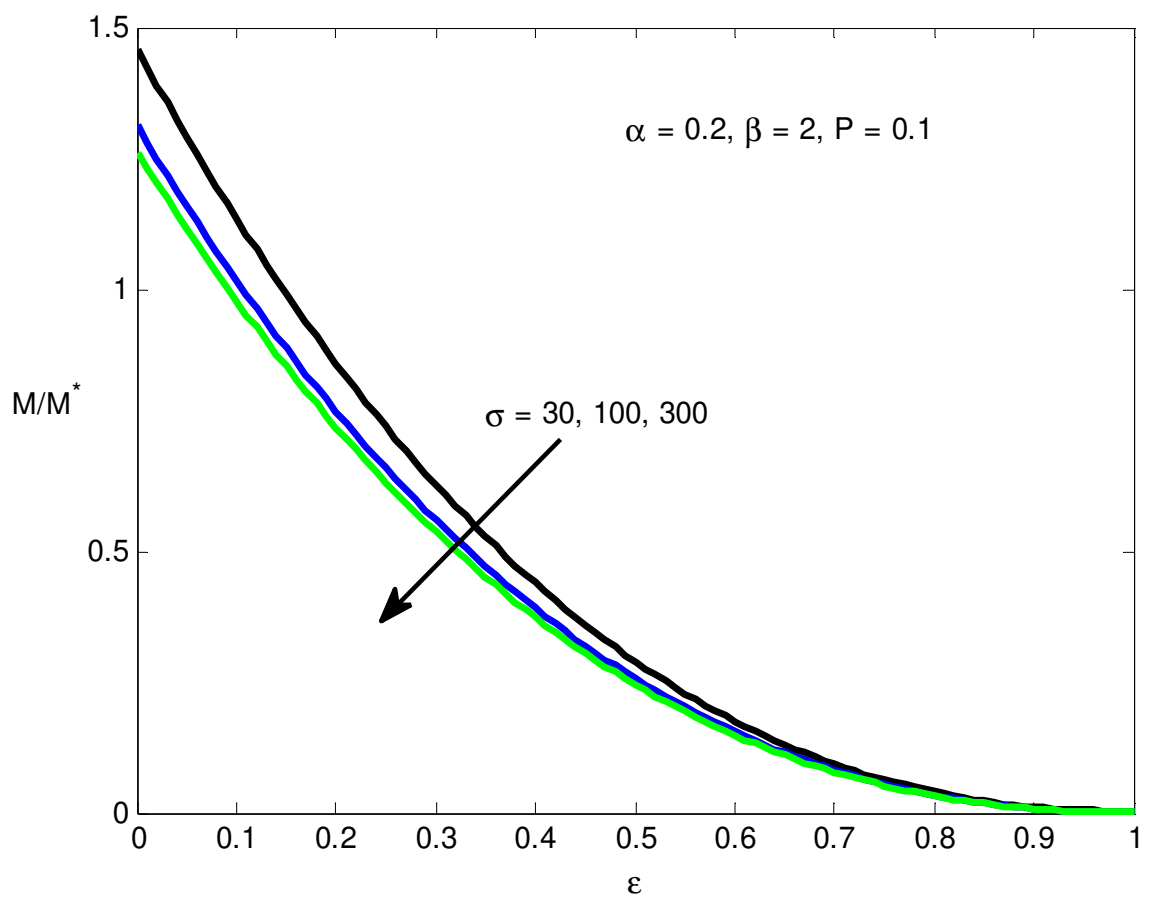

Figure 8:The Impact of $\sigma$ on the Mass Flow Rate $M / M^{*}$ for $\alpha=0.2$ 


\section{REFERENCES}

1. G.S. Beavers and D.D. Joseph, Boundary conditions at a naturally permeable bed, J.Fluid Mech., 30, 197207, 1967.

2. M. Krishna Murthy, S. Sreenadh, P. Lakshminarayana, G. Sucharitha, B. Rushikumar, Thermophoresis and Brownian motion effects on three dimensional MHD slip flow of a Cassonnanofluid over an exponentially stretching sheet, J. Nanofluid, 8, 1267-1272, 2019.

3. M. Krishna Murthy, C.S.K. Raju, V. Nagendramma, S.A. Shehzad, Ali J Chamka, MHD boundary layer slip Casson fluid flow over a dissipated stretched cylinder, Def. Diff. Forum, 393, 73-82, 2019.

4. Rao, P. Srinivasa, and G. Bhanodaya Reddy. "Effect of reflux on peristaltic motion in an asymmetric channel with partial slip and different wave forms." International journal of mechanical engineering (IJME) 3 (2014): 35-48.

5. M. Krishna Murthy, B. Madhusudhana Rao, N. Siva Kumar, B. Rushi Kumar, C.S.K. Raju, Slip effects on MHD three dimensional flow of Casson fluid over an exponentially stretching surface, J. Phys: Conference Series, 1000, 012156, 2018.

6. HYMAVATHI, T., and W. SRIDHAR. "NUMERICAL STUDY OF FLOW AND HEAT TRANSFER OF CASSON FLUID OVER AN EXPONENTIALLY POROUS STRETCHING SURFACE IN PRESENCE OF

THERMAL RADIATION." International Journal of Mechanical and Production Engineering Research and Development (IJMPERD) 8. 4, Aug 2018, 1145-1154

7. M. Krishna Murthy, MHD three dimensional flow of Casson fluid over an unsteady exponentially stretching sheet with slip conditions, Def. Diff. Forum, 388, 77-95, 2018.

8. M. Krishna Murthy, N. Mahesh Babu, R.L.V. Renuka Devi, M. Eswara Rao, Hydromagnetic flow of Casson fluid through a vertical deformable porous stratum with viscous dissipation and chemical reaction, Int. J. Mech. Eng. Tech, 9, 846-854, 2018.

9. Babu, D. Vidyanadha, and M. SURYANARAYANA REDDY. "Effects of Thermal Radiation and Viscous Dissipation on Powell-EyringNanofluid with Variable Thickness." International Journal of Mechanical and Production Engineering Research and Development (IJMPERD) 7.4 (2017): 389-402.

10. M. Krishna Murthy, M. Eswara Rao, R.L.V. Renuka Devi, N. Mahesh Babu, Effects of heat and mass transfer flow of a Jeffrey fluid through a vertical deformable porous stratum, Int. J. Mech. Eng. Tech, 9, 228-235, 2018.

11. S. Sreenadh, K.V. Prasad, H. Vaidya, E. Sudhakara, G. Gopi Krishna, M. Krishna Murthy, MHD Couette flow of a Jeffrey fluid over a deformable porous layer, Int. J. Appl. Comp. Math., 3, 2125-2138, 2017.

12. IKEOKWU, ENYINNAYA SAMUEL. "MARKING GENDER DIFFERENCES IN LITERARY DIALOGUE: A LINGUISTIC STUDY OF TWO CONTEMPORARY IGBO PLAYS." International Journal of English and Literature (IJEL) 3. 4, Oct 2013, 23-36 
13. M. Eswara Rao, M. Krishna Murthy, S. Sreenadh, E. Sudhakara, Effect of heat transfer on free surface flow of a Jeffrey fluid over a deformable permeable bed, Middle-East J. Sci. Res., 24, 603-612, 2016.

14. M. Krishna Murthy, MHD Couette flow of Jeffrey fluid in a porous channel with heat source and chemical reaction, Middle-East J. Sci. Res., 24, 585-592, 2016. 